\section{Cellular Physiology} and Biochemistry Published online: December 10, 2015

Accepted: November 13, 2015

This article is licensed under the Creative Commons Attribution-NonCommercial-NoDerivatives 4.0 Interna-

\title{
TIPE2 Mediates the Suppressive Effects of Shikonin on MMP13 in Osteosarcoma Cells
}

\author{
Biyong Deng Youwei Feng Bixiang Deng
}

Department of Orthopedics, Guizhou Province Osteological Hospital, Guiyang, China

\section{Key Words}

Osteosarcoma (OS) • Shikonin • Matrix metalloproteinase (MMP)-13 • TIPE2

\begin{abstract}
:
Background/Aims: Osteosarcoma (OS) is a primary malignant bone tumor in humans, and is notorious mainly for its distal metastases. We have recently shown that Shikonin, an effective constituent extracted from Chinese medicinal herb, inhibits OS cell invasion through suppression of matrix metalloproteinase 13 (MMP13). However, the underlying mechanisms remain unknown. Methods: Here, we studied the levels of tumor necrosis factor (TNF)alpha-induced protein 8-like 2 (TIPE2) in OS cells upon Shikonin treatment. TIPE2 levels were adapted in OS cell lines through transfection with plasmids carrying transgene or shorthairpin interference RNA (shRNA), and the effects of TIPE2 adaptation on MMP13 and cell invasiveness were evaluated by RT-qPCR, Western blot, ELISA and transwell cell migration assay, respectively. TIPE2 levels in OS specimens from patients were examined and correlated with cancer metastases and patient survival. Results: We found that Shikonin dose-dependently decreased MMP13 levels, and increased TIPE2 levels in two OS cell lines, U2OS and SaOS-2. Overexpression of TIPE2 in U2OS significantly suppressed MMP13 levels and cell invasiveness. Depletion of TIPE2 in SaOS-2 cells significantly increased MMP13 levels and cell invasiveness. Moreover, TIPE2 levels in OS specimens were significantly decreased, compared to adjacent non-cancer bone tissue. Lower TIPE2 levels correlated with higher incidence of metastases and worse 5-year survival. Conclusion: TIPE2 mediates the suppressive effects of Shikonin on MMP13 in osteosarcoma cells, and TIPE2 may be a novel therapeutic target for OS.
\end{abstract}

(C) 2015 The Author(s)

Published by S. Karger AG, Basel

\section{Introduction}

Osteosarcoma (OS) is a primary malignant bone tumor in humans, and is notorious mainly for its distal metastases [1-6]. In the past years, the advances in chemotherapy has assisted general surgery to substantially improve the long-term survival of patients with nonmetastatic OS. However, the survival rate for patients with metastatic OS remains low [1-15].

Bixiang Deng

KARGER 125
Department of Orthopedics, Guizhou Province Osteological Hospital, 25 Shachong S Rd, Guiyang 550007, (China)

Tel.+8685166307304, E-Mail bing_qiu15@163.com 


\section{Cellular Physiology Cell Physiol Biochem 2015;37:2434-2443 \begin{tabular}{l|l|l} 
and Biochemistry Published $10.1159 / 000438596$ & (c) 2015 The Author(s). Published by S. Karger AG, Basel \\
www.karger.com/cpb
\end{tabular} \\ Deng/Feng/Deng: Shikonin Inhibits MMP13 in OS through TIPE2}

Hence, elucidation of the molecular regulation of OS invasiveness as well as identification of novel therapeutic targets are critical for an effective OS therapy.

The extracellular matrix (ECM) plays a central role during tumor invasion. In line with these notions, the secreting proteolytic enzymes like matrix metalloproteinases (MMPs) digest ECM to allow cancer cell to invade and migrate [16]. MMP13 [17-22] has been shown to be expressed in OS cells, and appears to be an attractive target for suppressing invasiveness of OS cells.

Shikonin is a purified constituent from a Chinese medicinal herb Lithospermum erythrorhixon [23-25]. Shikonin has demonstrated anti-tumor potent, in which it induces cancer cell apoptosis and necroptosis [23-25]. Recently, we reported that high-dose of Shikonin had prompt but profound anti-tumor effect on both primary and metastatic OS, through inducing RIP1 and RIP3-dependent cancer cell necroptosis [26]. Moreover, Shikonin inhibits OS cell invasion through suppression of MMP13 [27]. However, the underlying mechanisms remain unknown.

Tumor necrosis factor (TNF)-alpha-induced protein 8-like 2 (TIPE2) was first identified from inflamed spinal cords of experimental autoimmune encephalomyelitis (EAE) mouse model [28]. TIPE2 has been first identified as a novel immune negative molecule that appears to be critical to homeostasis maintenance in the adaptive and innate immunity [29]. Later on, TIPE2 has been found to inhibit inducible nitric oxide synthase (iNOS) and NO generation, and consequently suppress inflammation by switching arginine metabolism from nitric oxide synthase to arginase [30], and thus has a role in macrophage polarization [6, 31-36]. The dysregulation of TIPE2 has also been found to mediate diverse immunological diseases [37-41]. Recently, involvement of loss of TIPE2 has been suggested in the carcinogenesis of different cancer, including Non-small cell lung cancer [42], hepatocellular carcinoma [43, 44], renal cell carcinoma [45], etc. However, whether TIPE2 may be involved in the pathogenesis of OS has not been reported.

Here, we found that Shikonin dose-dependently decreased MMP13 levels, and increased TIPE2 levels in two OS cell lines, U2OS and SaOS-2. Overexpression of TIPE2 in U20S significantly suppressed MMP13 levels and cell invasiveness. Depletion of TIPE2 in SaOS-2 cells significantly increased MMP13 levels and cell invasiveness. Moreover, TIPE2 levels in OS specimens were significantly decreased, compared to adjacent non-cancer bone tissue. Lower TIPE2 levels correlated with higher incidence of metastases and worse 5-year survival.

\section{Materials and Methods}

\section{Patient tissue specimens}

Resected 36 OS specimens (paired OS and the adjacent non-cancer bone tissue (NT)) in this study were histologically and clinically diagnosed at the Guizhou Province Osteological Hospital from 2010 to 2014. For the use of these clinical materials for research purposes, prior patient's consents and approval from the Institutional Research Ethics Committee were obtained. The OS specimens were further separated into two groups based on presence of distal cancer metastases or not. The resected OS specimens and NT were confirmed independently by two experienced pathologists, and the tissue were chopped into small pieces, crashed and used for extraction of protein as shown before in the Western blot part.

Culture and transfection of human OS cell lines

U2OS and SaOS-2 are two widely used human OS cell lines purchased from American Type Culture Collection (ATCC, Rockville, MD, USA), and were cultured in Dulbecco's Modified Eagle's Medium (DMEM, Invitrogen, Carlsbad, CA, USA) supplemented with 10\% fetal bovine serum (FBS; Sigma-Aldrich, St Louis, MO, USA) in a humidified chamber with $5 \% \mathrm{CO}_{2}$ at $37^{\circ} \mathrm{C}$. U2OS cells were derived by J. Ponten and E. Saksela in 1964 from a moderately differentiated sarcoma of the tibia of a 15 year old girl [46]. SaOS-2 is one of an extensive series of human tumor lines isolated and characterized by J. Fogh and G. Trempe from a 11 year 


\section{Cellular Physiology Cell Physiol Biochem 2015;37:2434-2443

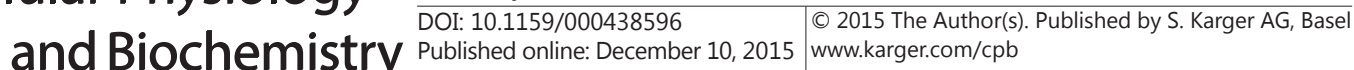 \\ Deng/Feng/Deng: Shikonin Inhibits MMP13 in OS through TIPE2}

old girl [47]. We chose these two lines since SaOS-2 cells express TIPE2, while U2OS cells do not. U2OS cells were transfected with plasmids carrying either a TIPE2 transgene, or a scrambled sequence (scr) as a control, and got a more than $95 \%$ of transfection efficiency, based on the expression of a co-transgene, green fluorescence protein (GFP). SaOS-2 cells were transfected with plasmids carrying either a short-hairpin interfering RNA for TIPE2 (shTIPE2), or a scrambled sequence (scr) as a control, and got a more than 95\% of transfection efficiency, based on the expression of a co-transgene, green fluorescence protein (GFP). The human TIPE2 transgene was amplified from human peripheral blood mononuclear cells using TIPE2specific primers (TIPE2-Foward, 5'-gtgactgaccacatacccca-3' and TIPE2-Reverse, 5'-agtgttagtgccaggtgagc-3'), subcloned into pscAAV-GFP cloning vector, and then sequenced to confirm the correct insertion. The sequence of shTIPE2 is 5'-GAAGTGAAACTCAGGTCCG-3'. Transfections were performed with Lipofectamine 2000 reagent (Invitrogen), according to the manufacturer's instructions.

\section{Shikonin}

Shikonin (>98\%) was purchased from Shanghai Tauto Biotech Co., Ltd. Stock solution at $50 \mathrm{mmol} / \mathrm{l}$ was made in dimethyl sulfoxide (DMSO; Sigma-Aldrich, St. Louis, MO, USA) and stored in the dark at $-20^{\circ} \mathrm{C}$. The final Shikonin concentrations used for different experiments were prepared by diluting the stock solution with culture media. Shikonin was used to treat cells for 24 hours before analysis in FBS-containing complete media.

\section{Transwell cell migration assay}

The transwell cell migration assay was performed using a Fluorometric Cell Migration Assay kit with polycarbonate membrane inserts ( $5 \mu \mathrm{m}$ pore size; Cell Biolabs, San Diego, CA, USA). Cells were serumstarved overnight in DMEM prior to initiation of the experiment. The lower chambers were filled with $1 \mathrm{ml}$ of conditioned media. Cells $\left(4 \times 10^{4}\right)$ were re-suspended in $200 \mu \mathrm{l}$ of DMEM and added to the upper chamber. Cells were then incubated at $37^{\circ} \mathrm{C}$ for 24 hours to allow cell migration through the membrane. Migratory cells were detached from the underside of the membrane and subsequently lysed and detected by CyQuant GR dye (Invitrogen). Fluorescence measurement was performed in a FluoStar Optima fluorescence plate reader with a $485 / 520 \mathrm{~nm}$ filter set.

\section{RNA extraction, reverse transcription and quantitative RT-PCR}

Total RNA was extracted from the cultured cells using RNeasy kit (Invitrogen), according to the manufacturer's instruction. For mRNA analysis, complementary DNA (cDNA) was randomly primed from $2 \mu \mathrm{g}$ of total RNA using the Omniscript reverse transcription kit (Qiagen, Hilden, Germany). Quantitative Real-time PCR (RT-qPCR) was subsequently performed in duplicate with a 1:4 dilution of cDNA using the Quantitect SyBr green PCR system (Qiagen). Primers are: TIPE2-Forward: 5'-gactgaccacataccccactc-3'; TIPE2-Reverse: 5'-tcaccaaagctaagtgccgt-3'; MMP13-Forward: 5'-CCCAGGAATTGGTGATAAAG-3'; MMP13Reverse: 5'-ATTACCCCAAATGCTCTTCA-3'; $\alpha$-tubulin-Forward: 5'-CCAAGCTGGAGTTCTCTA -3'; $\alpha$-tubulinReverse: 5'-CAGAGTGCTCCAGG-3'. Data were collected and analyzed using $2^{-\triangle \triangle C t}$ method for quantification of the relative mRNA expression levels. Values of genes were first normalized against $\alpha$-tubulin, and then compared to the experimental controls.

\section{Western blot}

The protein was extracted from cell lysates after homogenization with RIPA lysis buffer (1\% NP40, $0.1 \%$ SDS, $100 \mu \mathrm{g} / \mathrm{ml}$ phenylmethylsulfonyl fluoride, $0.5 \%$ sodium deoxycholate, in PBS) on ice. The supernatants were collected after centrifugation at $12000 \times \mathrm{g}$ at $4{ }^{\circ} \mathrm{C}$ for $20 \mathrm{~min}$. Protein concentration was determined using a BCA protein assay kit (Bio-rad, China), and whole lysates were mixed with $4 \times$ SDS loading buffer (125 mmol/l Tris-HCl, 4\% SDS, 20\% glycerol, 100mmol/l DTT, and 0.2\% bromophenol blue) at a ratio of 1:3. Protein samples were heated at $100^{\circ} \mathrm{C}$ for $5 \mathrm{~min}$ and were separated on SDS-polyacrylamide gels. The separated proteins were then transferred to a PVDF membrane. The membrane blots were first probed with a primary antibody. After incubation with horseradish peroxidase-conjugated second antibody, autoradiograms were prepared using the enhanced chemiluminescent system to visualize the protein antigen. The signals were recorded using X-ray film. Primary antibodies for Western Blot are anti-TIPE2, anti-MMP13 and $\alpha$-tubulin (all from Cell Signaling, San Jose, CA, USA). $\alpha$-tubulin was used as protein loading controls. Secondary antibody is HRP-conjugated anti-rabbit (Jackson ImmunoResearch Labs, West Grove, 


\section{Cellular Physiology Cell Physiol Biochem 2015;37:2434-2443

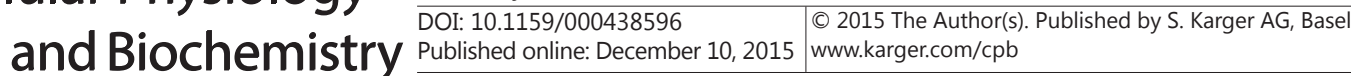 \\ Deng/Feng/Deng: Shikonin Inhibits MMP13 in OS through TIPE2}

PA, USA). Images shown in the figures were representative from 5 individuals. Densitometry of Western blots was quantified with NIH ImageJ software. The protein levels were first normalized to $\alpha$-tubulin, and then normalized to experimental controls.

ELISA

The concentration of MMP13 in the conditioned media from cultured cells was determined by a MMP13 ELISA Kit (Calbiochem/Oncogene, Cambridge, MA, USA). ELISA was performed according to the instructions of the manufacturer. Briefly, the collected condition media were added to a well coated with MMP13 polyclonal antibody, and then immunosorbented by biotinylated monoclonal anti-human MMP13 antibody at room temperature for 2 hours. The color development catalyzed by horseradish peroxidase was terminated with $2.5 \mathrm{~mol} / \mathrm{l}$ sulfuric acid and the absorption was measured at $450 \mathrm{~nm}$. The protein concentration was determined by comparing the relative absorbance of the samples with the standards.

\section{Statistics}

All data were statistically analyzed using one-way ANOVA with a Bonferroni correction, followed by Fisher's Exact Test for comparison of two groups (GraphPad Prism, GraphPad Software, Inc. La Jolla, CA, USA). Kaplan-Meier curves were sued to analyze the patient survival by miR-429 levels. All values are depicted as mean \pm standard deviation and are considered significant if $\mathrm{p}<0.05$.

\section{Results}

Shikonin dose-dependently suppresses MMP13 and increases TIPE2 in OS cells

In order to examine the mechanisms underlying the suppressive effects of Shikonin on MMP13 in OS cells, we selected two commonly used human OS cell lines, U2OS and SaOS-2, which are TIPE2-negative and TIPE2-positive, respectively. Then we checked the effects of

Fig. 1. Shikonin dose-dependently suppresses MMP13 and increases TIPE2 in OS cells. We checked the effects of Shikonin at low doses $\quad(0.01 \mu \mathrm{mol} / \mathrm{l}$, $0.1 \mu \mathrm{mol} / \mathrm{l}$ and $1 \mu \mathrm{mol} / \mathrm{l}$ ) to the cultured SaOS-2 and U20S cells. (A-C) MMP13 and TIPE2 levels in SaOS-2 cells by Shikonin treatment, shown by Representative Western blots for (A), and by quantification (B-C). (D-F) MMP13 and TIPE2 levels in U2OS cells by Shikonin treatment, shown by Representative Western blots for (D), and by quantification (E-F). ${ }^{*} \mathrm{p}<0.05 . \mathrm{N}=5$.

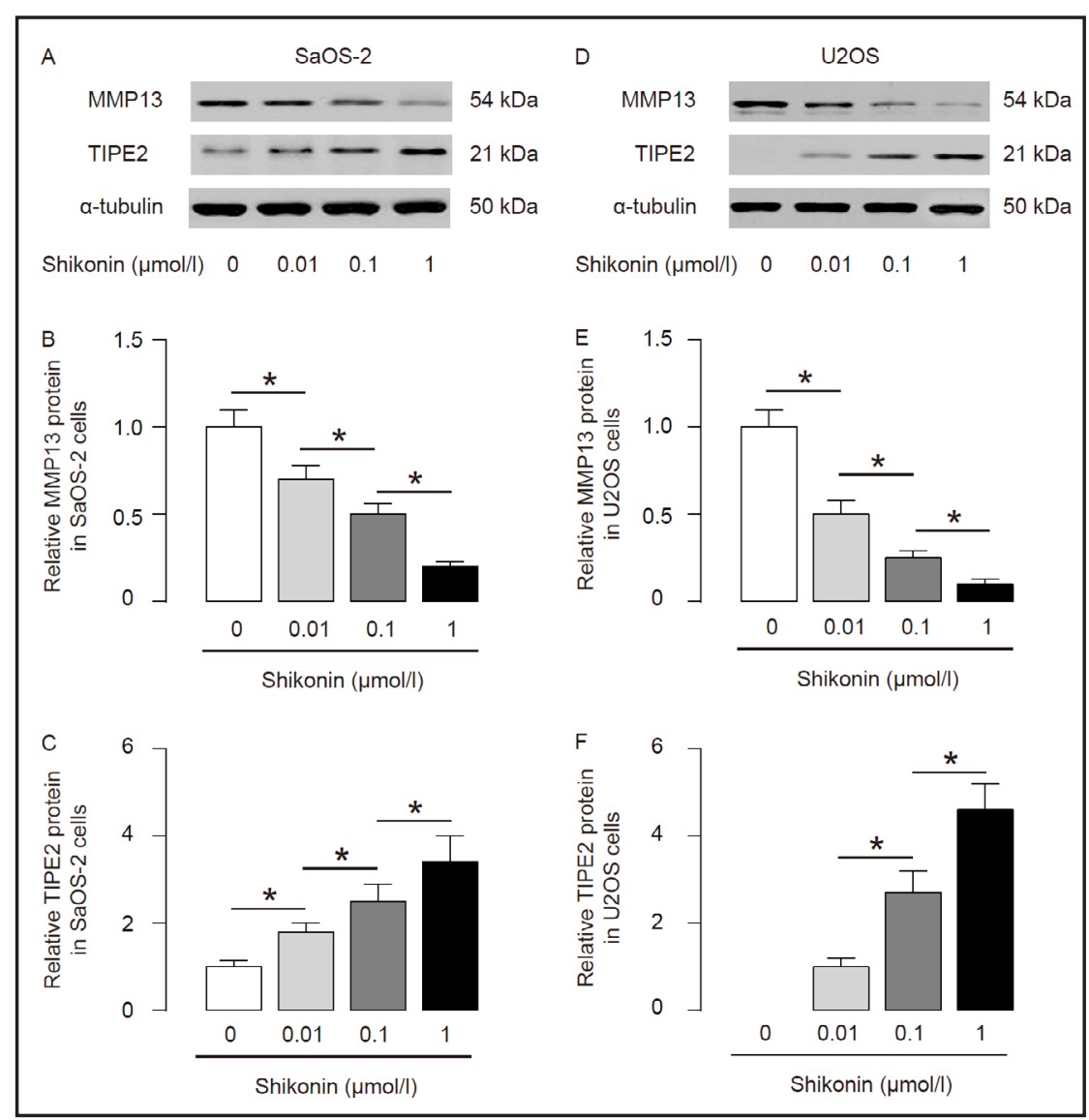


Fig. 2. TIPE2 overexpression inhibits MMP13 in U2OS cells. We transfected U2OS cells with either a TIPE2-overexpressing plasmid, or a control plasmid carrying a scrambled sequence (scr). (A) Overexpression of TIPE2 in U20S cells was confirmed by RT-qPCR. (B-D) Overexpression of TIPE2 in U20S cells significantly decreased MMP13 levels, by RT-qPCR (B), by Western blot (C), and by ELISA on the secreted protein in the conditioned media (D). (E-F) The suppression of MMP13 by TIPE2 overexpression resulted in a significant reduction in cell invasiveness, in a transwell cell migration assay, shown by quantification (E), and by representative images $(\mathrm{F}) .{ }^{*} \mathrm{p}<0.05$. $\mathrm{N}=5$. Scale bars are $20 \mu \mathrm{m}$.

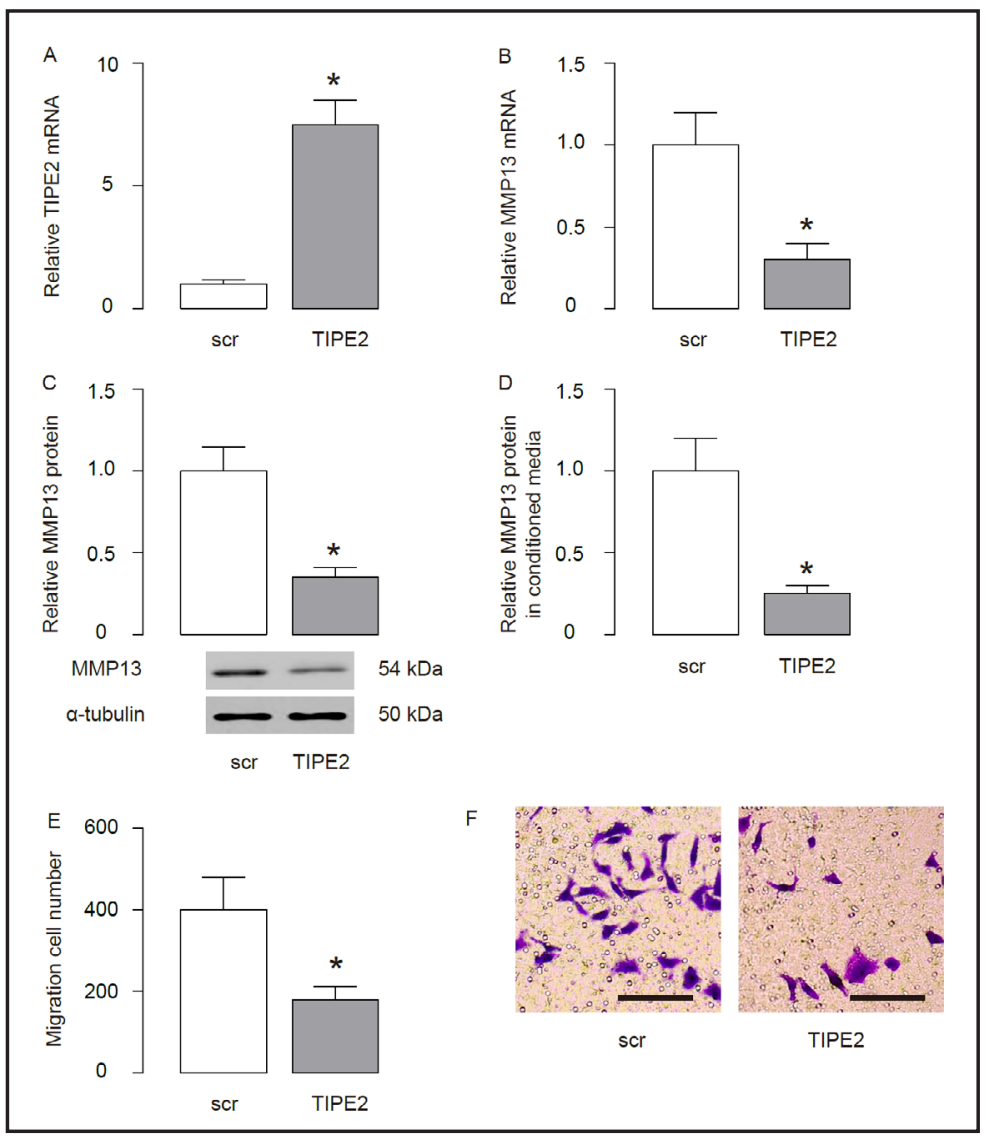

Shikonin at low doses $(0.01 \mu \mathrm{mol} / \mathrm{l}, 0.1 \mu \mathrm{mol} / \mathrm{l}$ and $1 \mu \mathrm{mol} / \mathrm{l})$ to the cultured SaOS-2 and U20S cells. We found that Shikonin dose-dependently decreased the cellular MMP13 levels in SaOS-2 cells, shown by representative Western blots (Fig. 1A), and by quantification (Fig. 1B). Moreover, we found that Shikonin dose-dependently increased the TIPE2 levels in SaOS-2 cells, shown by representative Western blots (Fig. 1A), and by quantification (Fig. 1C). Similarly, Shikonin dose-dependently decreased the cellular MMP13 levels in U2OS cells, shown by representative Western blots (Fig. 1C), and by quantification (Fig. 1D). Moreover, Shikonin dose-dependently increased the TIPE2 levels in U20S cells, shown by representative Western blots (Fig. 1C), and by quantification (Fig. 1E). Thus, regardless of endogenous TIPE2 levels, Shikonin dose-dependently suppresses MMP13 and increases TIPE2 in OS cells.

TIPE2 overexpression inhibits MMP13 in U2OS cells

In order to find out whether Shikonin indeed inhibits MMP13 in OS cells through TIPE2, we overexpressed TIPE2 in U2OS cells to evaluate its effects on the Shikonin-induced suppression of MMP13. Thus, we transfected U2OS cells with either a TIPE2-overexpressing plasmid, or a control plasmid carrying a scrambled sequence (scr). First, overexpression of TIPE2 in U2OS cells was confirmed by RT-qPCR (Fig. 2A). We found that overexpression of TIPE2 in U2OS cells significantly decreased MMP13 levels, by RT-qPCR (Fig. 2B), by Western blot (Fig. 2C), and by ELISA on the secreted protein in the conditioned media (Fig. 2D). Moreover, the suppression of MMP13 by TIPE2 overexpression resulted in a significant reduction in cell invasiveness, in a transwell cell migration assay (Fig. 2E-F).

TIPE2 depletion activates MMP13 in SaOS-2 cells

In a loss-of-function approach, we inhibited TIPE2 in SaOS-2 cells to evaluate its effects on the Shikonin-induced suppression of MMP13. Thus, we transfected SaOS-2 cells with KARGER 
Fig. 3. TIPE2 depletion activates MMP13 in SaOS-2 cells. We transfected SaOS2 cells with either a plasmid carrying shTIPE2, or a control plasmid carrying a scrambled sequence (scr). (A) Depletion of TIPE2 in SaOS-2 cells was confirmed by RT-qPCR. (B-D) Depletion of TIPE2 in SaOS-2 cells significantly increased MMP13 levels, by RT-qPCR (B), by Western blot (C), and by ELISA on the secreted protein in the conditioned media (D). (E-F) The activation of MMP13 by TIPE2 inhibition resulted in a significant increase in cell invasiveness in SaOS2 cells, in a transwell cell migration assay, shown by quantification (E), and by representative images (F). ${ }^{*} \mathrm{p}<0.05$. N=5. Scale bars are $20 \mu \mathrm{m}$.

Fig. 4. TIPE2 levels in OS specimens. TIPE2 levels in 36 OS specimens were then analyzed by Western blot, compared to adjacent non-cancer bone tissue. Moreover, OS specimens were further separated into 2 groups, according to the presence of distal metastases (Meta) or not (no Meta). (A) OS contained significantly lower levels of
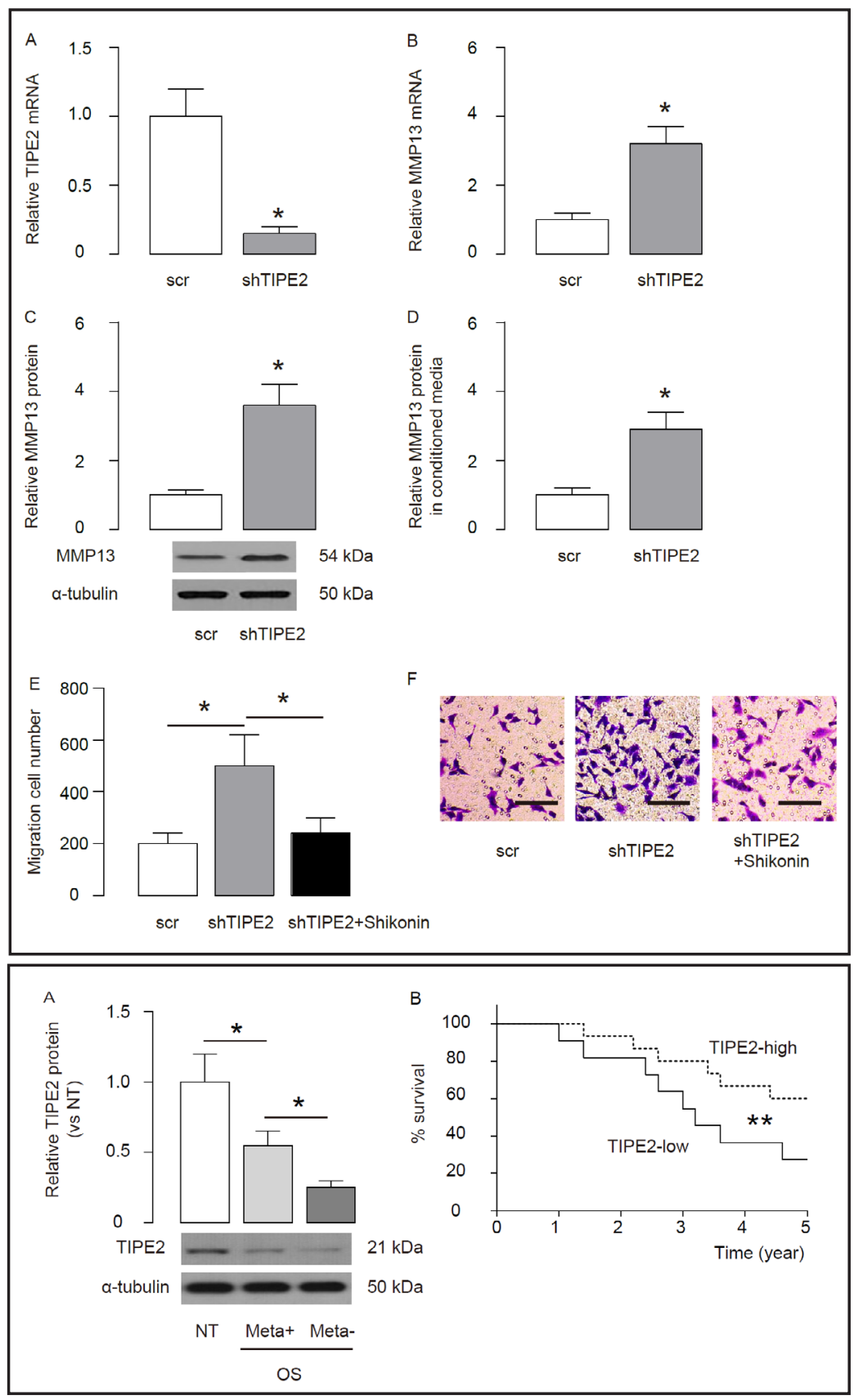

TIPE2, compared to NT. Moreover, the TIPE2 levels in OS with distal metastases were significantly lower than OS without distal metastases. (B) The 36 patients were followed-up for 5 years. The median value of all 36 cases was chosen as the cutoff point for separating TIPE2-high cases $(n=18)$ from TIPE2-low cases $(\mathrm{n}=18)$. Kaplan-Meier curves were performed, showing that TIPE2-low OS patients had a worse 5-year survival, compared to TIPE2-high OS patients. ${ }^{*} \mathrm{p}<0.05 .{ }^{* *} \mathrm{p}<0.01$. $\mathrm{N}=5$.

either a plasmid carrying shTIPE2, or a control plasmid carrying a scrambled sequence (scr). First, depletion of TIPE2 in SaOS-2 cells was confirmed by RT-qPCR (Fig. 3A). We found that depletion of TIPE2 in SaOS-2 cells significantly increased MMP13 levels, by RT-qPCR (Fig. 3B), by Western blot (Fig. 3C), and by ELISA on the secreted protein in the conditioned media (Fig. 3D). Moreover, the activation of MMP13 by TIPE2 depletion resulted in a significant 


\section{Cellular Physiology Cell Physiol Biochem 2015;37:2434-2443 \begin{tabular}{l|l|l} 
and Biochemistry & DOI: 10.1159/000438596 2015 The Author(s). Published by S. Karger AG, Basel \\
Published & (c)
\end{tabular}

Fig. 5. A schematic model. TIPE2 may mediate the suppressive effects of Shikonin on MMP13 in osteosarcoma cells.

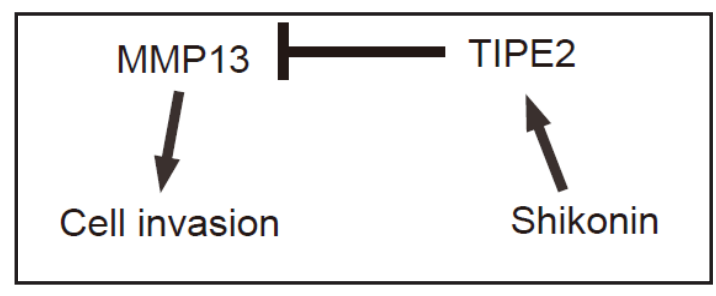

increase in cell invasiveness, in a transwell cell migration assay (Fig. 3E-F). Furthermore, treatment of TIPE2-depleted SaOS- 2 cells with $1 \mu \mathrm{mol} / \mathrm{l}$ of Shikonin abolished the increases in cell invasion by TIPE2 depletion (Fig. 3E-F).

TIPE2 levels in OS specimens

TIPE2 levels in 36 OS specimens were then analyzed, compared to adjacent non-cancer bone tissue. Moreover, OS specimens were further separated into 2 groups, according to the presence of distal metastases (Meta) or not (no Meta). The protein levels of TIPE2 were determined in the specimens by Western blot. We found that OS contained significantly lower levels TIPE2, compared to NT. Moreover, the TIPE2 levels in OS with distal metastases were significantly lower than OS without distal metastases (Fig. 4A). Next, we investigated whether the levels of TIPE2 may correlate with overall survival of OS patients. After resection of the tumor, the 36 patients were followed-up for 5 years. The median value of all 36 cases was chosen as the cutoff point for separating TIPE2-high cases $(n=18)$ from TIPE2-low cases $(\mathrm{n}=18)$. Kaplan-Meier curves were performed, showing that TIPE2-low OS patients had a worse 5-year survival, compared to TIPE2-high OS patients (Fig. 4B). Thus, lower TIPE2 levels seem to indicate higher incidence of metastases and worse 5-year survival. Together, our study suggests that TIPE2 may mediate the suppressive effects of Shikonin on MMP13 in osteosarcoma cells (Fig. 5).

\section{Discussion}

High-dose Shikonin induces cancer cell necroptosis in OS, while delivery of high-dose Shikonin locally into the OS may be challenging and could have potent side-effects [23-25]. Thus, in our previous study and here, we analyzed the effects of low-dose Shinkonin on the invasiveness of OS, as well as the underlying mechanisms. We have shown that Shikonin dosedependently decreased MMP13 levels in OS cells, resulting in suppression of invasiveness in both scratch wound healing assay and transwell cell migration assay. Here, we further showed that Shikonin dose-dependently increased TIPE2 levels in OS cells.

Previous studies have shown that TIPE2 is a novel anti-inflammatory factor involved in immune negative regulation and homeostasis maintenance [28, 29]. TIPE2 is not detectable or weakly expressed in most human cancer cells, compared to their expression in non-cancer cells $[28,29]$. Thus, TIPE2 may be a tumor-suppressor and its loss may facilitate human cancer progression. Indeed, accumulating evidence has highly suggested a pivotal role of TIPE2 in cancer [42-45]. However, the information about the cell-autonomous role of TIPE2 in human cancers is limited.

Here, we showed compelling data on the low expression of TIPE2 in OS tissue, especially in those OS with distal metastases. Most interestingly, TIPE2 was recovered in OS cells by Shikonin in a dose-dependent manner. In both loss-of-function and gain-offunction approaches, we found that TIPE2 directly regulated MMP13 levels in an inverse way. Together with previous reports, these data demonstrate a potential anti-OS role of Shikonin, and suggest that Shikonin not only induces cell death of OS cells but also inhibits OS cell invasion through TIPE2 re-expression. Since we have examined two OS lines with distinct expression levels of TIPE2, and have got essentially similar results, our approaches thus should be able to rule out a possibility of our findings to be cell-line dependent. 


\section{Cellular Physiology Cell Physiol Biochem 2015;37:2434-2443 \begin{tabular}{l|l|l|l|l}
\hline DOI: 10.1159/000438596 & $\begin{array}{l}\text { C) } 2015 \text { The Author(s). Published by S. Karger AG, Basel } \\
\text { www.karger.com/cpb }\end{array}$
\end{tabular} \\ Deng/Feng/Deng: Shikonin Inhibits MMP13 in OS through TIPE2}

Since TIPE2 appeared to have effects on both mRNA and protein of MMP13, it may be hypothesized that TIPE2 may directly regulate the gene expression of MMP13, rather than the posttranslational modification of MMP13 protein. Thus, TIPE2 may activate a nuclear machinery to directly affect the promoter of MMP13.

Recently, Zhang et al. showed that TNF-alpha clearly augments MMP-13/MMP-3 expression and promotes cell migration in HepG2 cells through activation of the Erk1/2NF-kappaB pathways. Moreover, TIPE2 overexpression efficiently abrogates the effects of LPS on TNF-alpha secretion and abolishes the effects of TNF-alpha on MMP-13/MMP3 upregulation, cell migration and Erk1/2-NF-kappaB activation [48]. This study and ours together highlight a previous unappreciated role for TIPE2 in regulation of cancer invasion via MMPs modulation.

\section{Disclosure Statement}

The authors have declared that no competing interests exist.

\section{References}

1 Tsuchiya H, Tomita K, Mori Y, Asada N, Morinaga T, Kitano S, Yamamoto N: Caffeine-assisted chemotherapy and minimized tumor excision for nonmetastatic osteosarcoma. Anticancer Res 1998;18:657-666.

2 Yang J, Zhang W: New molecular insights into osteosarcoma targeted therapy. Curr Opin Oncol 2013;25:398-406.

3 Li G, Fu D, Liang W, Fan L, Chen K, Shan L, Hu S, Ma X, Zhou K, Cheng B: Cyc1 silencing sensitizes osteosarcoma cells to trail-induced apoptosis. Cell Physiol Biochem 2014;34:2070-2080.

4 Liu Y, He J, Chen X, Li J, Shen M, Yu W, Yang Y, Xiao Z: The proapoptotic effect of formononetin in human osteosarcoma cells: Involvement of inactivation of erk and akt pathways. Cell Physiol Biochem 2014;34:637-645.

5 Wang Q, Cai J, Wang J, Xiong C, Zhao J: Mir-143 inhibits egfr-signaling-dependent osteosarcoma invasion. Tumour Biol 2014;35:12743-12748.

6 Xiao Q Zhang X, Wu Y, Yang Y: Inhibition of macrophage polarization prohibits growth of human osteosarcoma. Tumour Biol 2014;35:7611-7616.

7 Luo XJ, Tang DG, Gao TL, Zhang YL, Wang M, Quan ZX, Chen J: Microrna-212 inhibits osteosarcoma cells proliferation and invasion by down-regulation of sox4. Cell Physiol Biochem 2014;34:2180-2188.

8 Li F, Li S, Cheng T: Tgf-beta1 promotes osteosarcoma cell migration and invasion through the mir-143versican pathway. Cell Physiol Biochem 2014;34:2169-2179.

9 He Y, Meng C, Shao Z, Wang H, Yang S: Mir-23a functions as a tumor suppressor in osteosarcoma. Cell Physiol Biochem 2014;34:1485-1496.

10 Chen J, Fu H, Wang Z, Yin F, Li J, Hua Y, Cai Z: A new synthetic ursolic acid derivative iua with antitumor efficacy against osteosarcoma cells via inhibition of jnk signaling pathway. Cell Physiol Biochem 2014;34:724-733.

11 Xu H, Liu X, Zhao J: Down-regulation of mir-3928 promoted osteosarcoma growth. Cell Physiol Biochem 2014;33:1547-1556.

12 Xu G, Wang J, Jia Y, Shen F, Han W, Kang Y: Mir-142-3p functions as a potential tumor suppressor in human osteosarcoma by targeting hmga1. Cell Physiol Biochem 2014;33:1329-1339.

13 Pan W, Wang H, Jianwei R, Ye Z: Microrna-27a promotes proliferation, migration and invasion by targeting map2k4 in human osteosarcoma cells. Cell Physiol Biochem 2014;33:402-412.

14 Chen X, Luther G, Zhang W, Nan G, Wagner ER, Liao Z, Wu N, Zhang H, Wang N, Wen S, He Y, Deng F, Zhang J, Wu D, Zhang B, Haydon RC, Zhou L, Luu HH, He TC: The e-f hand calcium-binding protein s100a4 regulates the proliferation, survival and differentiation potential of human osteosarcoma cells. Cell Physiol Biochem 2013;32:1083-1096.

15 Chang YW, Zhao YF, Cao YL, Gu XF, Li ZQ, Wang SQ Miao JH, Zhan HS: Liver x receptor alpha inhibits osteosarcoma cell proliferation through up-regulation of foxo1. Cell Physiol Biochem 2013;32:180-186. 


\section{Cellular Physiology Cell Physiol Biochem 2015;37:2434-2443

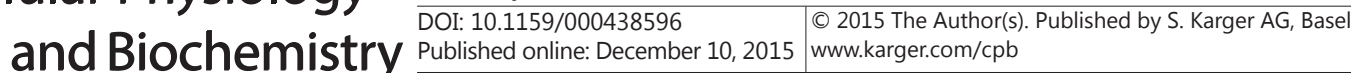 \\ Deng/Feng/Deng: Shikonin Inhibits MMP13 in OS through TIPE2}

16 Demuth T, Berens ME: Molecular mechanisms of glioma cell migration and invasion. J Neurooncol 2004;70:217-228.

17 Ryu B, Li Y, Qian ZJ, Kim MM, Kim SK: Differentiation of human osteosarcoma cells by isolated phlorotannins is subtly linked to cox-2, inos, mmps, and mapk signaling: Implication for chronic articular disease. Chem Biol Interact 2009;179:192-201.

18 Zhou Y, Hu Z, Li N, Jiang R: Interleukin-32 stimulates osteosarcoma cell invasion and motility via akt pathway-mediated mmp-13 expression. Int J Mol Med 2015;35:1729-1733.

19 Shang HS, Chang JB, Lin JH, Lin JP, Hsu SC, Liu CM, Liu JY, Wu PP, Lu HF, Au MK, Chung JG: Deguelin inhibits the migration and invasion of $\mathrm{u}-2$ os human osteosarcoma cells via the inhibition of matrix metalloproteinase-2/-9 in vitro. Molecules 2014;19:16588-16608.

20 Osaki M, Takeshita F, Sugimoto Y, Kosaka N, Yamamoto Y, Yoshioka Y, Kobayashi E, Yamada T, Kawai A, Inoue T, Ito H, Oshimura M, Ochiya T: Microrna-143 regulates human osteosarcoma metastasis by regulating matrix metalloprotease-13 expression. Mol Ther 2011;19:1123-1130.

21 Enomoto M, Hayakawa S, Itsukushima S, Ren DY, Matsuo M, Tamada K, Oneyama C, Okada M, Takumi T, Nishita M, Minami Y: Autonomous regulation of osteosarcoma cell invasiveness by wnt5a/ror2 signaling. Oncogene 2009;28:3197-3208.

22 Ma O, Cai WW, Zender L, Dayaram T, Shen J, Herron AJ, Lowe SW, Man TK, Lau CC, Donehower LA: Mmp13, birc2 (ciap1), and birc3 (ciap2), amplified on chromosome 9, collaborate with p53 deficiency in mouse osteosarcoma progression. Cancer Res 2009;69:2559-2567.

23 Andujar I, Rios JL, Giner RM, Recio MC: Pharmacological properties of shikonin - a review of literature since 2002. Planta medica 2013;79:1685-1697.

24 Andujar I, Recio MC, Giner RM, Rios JL: Traditional chinese medicine remedy to jury: The pharmacological basis for the use of shikonin as an anticancer therapy. Curr Med Chem 2013;20:2892-2898.

25 Wang R, Yin R, Zhou W, Xu D, Li S: Shikonin and its derivatives: A patent review. Expert Opin Ther Pat 2012;22:977-997.

26 Fu Z, Deng B, Liao Y, Shan L, Yin F, Wang Z, Zeng H, Zuo D, Hua Y, Cai Z: The anti-tumor effect of shikonin on osteosarcoma by inducing rip1 and rip3 dependent necroptosis. BMC Cancer 2013;13:580.

27 Deng B, Qiu B: Shikonin inhibits invasiveness of osteosarcoma through mmp13 suppression. Tumour Biol 2015 in press. DOI: 10.1007/s13277-015-3662-1.

28 Zhang X, Wang J, Fan C, Li H, Sun H, Gong S, Chen YH, Shi Y: Crystal structure of tipe2 provides insights into immune homeostasis. Nat Struct Mol Biol 2009;16:89-90.

29 Sun H, Gong S, Carmody RJ, Hilliard A, Li L, Sun J, Kong L, Xu L, Hilliard B, Hu S, Shen H, Yang X, Chen YH: Tipe2, a negative regulator of innate and adaptive immunity that maintains immune homeostasis. Cell 2008;133:415-426.

30 Lou Y, Zhang G, Geng M, Zhang W, Cui J, Liu S: Tipe2 negatively regulates inflammation by switching arginine metabolism from nitric oxide synthase to arginase. PLoS One 2014;9:e96508.

31 Xiao X, Gaffar I, Guo P, Wiersch J, Fischbach S, Peirish L, Song Z, El-Gohary Y, Prasadan K, Shiota C, Gittes GK: M2 macrophages promote beta-cell proliferation by up-regulation of smad7. Proc Natl Acad Sci U S A 2014;111:E1211-1220.

32 Song X, Xie S, Lu K, Wang C: Mesenchymal stem cells alleviate experimental asthma by inducing polarization of alveolar macrophages. Inflammation 2015;38:485-492.

33 Wang B, Miao Y, Zhao Z, Zhong Y: Inflammatory macrophages promotes development of diabetic encephalopathy. Cell Physiol Biochem 2015;36:1142-1150.

34 Pan B, Liu G, Jiang Z, Zheng D: Regulation of renal fibrosis by macrophage polarization. Cell Physiol Biochem 2015;35:1062-1069.

35 Liu W, Zhang S, Gu S, Sang L, Dai C: Mesenchymal stem cells recruit macrophages to alleviate experimental colitis through tgfbeta1. Cell Physiol Biochem 2015;35:858-865.

36 Lin S, Qiu M, Chen J: Il-4 modulates macrophage polarization in ankylosing spondylitis. Cell Physiol Biochem 2015;35:2213-2222.

37 Li D, Song L, Fan Y, Li X, Li Y, Chen J, Zhu F, Guo C, Shi Y, Zhang L: Down-regulation of tipe2 mrna expression in peripheral blood mononuclear cells from patients with systemic lupus erythematosus. Clin Immunol 2009;133:422-427. 


\section{Cellular Physiology Cell Physiol Biochem 2015;37:2434-2443 \begin{tabular}{ll|l|l|l} 
DOI: 10.1159/000438596 & $\begin{array}{l}\text { O } 2015 \text { The Author(s). Published by S. Karger AG, Basel } \\
\text { www.karger.com/cpb }\end{array}$
\end{tabular} \\ Deng/Feng/Deng: Shikonin Inhibits MMP13 in OS through TIPE2}

38 Xi W, Hu Y, Liu Y, Zhang J, Wang L, Lou Y, Qu Z, Cui J, Zhang G, Liang X, Ma C, Gao C, Chen Y, Liu S: Roles of tipe2 in hepatitis b virus-induced hepatic inflammation in humans and mice. Mol Immunol 2011;48:12031208.

39 Zhang Y, Wei X, Liu L, Liu S, Wang Z, Zhang B, Fan B, Yang F, Huang S, Jiang F, Chen YH, Yi F: Tipe2, a novel regulator of immunity, protects against experimental stroke. J Biol Chem 2012;287:32546-32555.

40 Kong L, Liu K, Zhang YZ, Jin M, Wu BR, Wang WZ, Li W, Nan YM, Chen YH: Downregulation of tipe2 mrna expression in peripheral blood mononuclear cells from patients with chronic hepatitis c. Hepatol Int 2013;7:844-849.

41 Ma Y, Liu X, Wei Z, Wang X, Wang Z, Zhong W, Li Y, Zhu F, Guo C, Zhang L, Wang X: The expression and significance of tipe2 in peripheral blood mononuclear cells from asthmatic children. Scand J Immunol 2013;78:523-528.

42 Li Y, Li X, Liu G, Sun R, Wang L, Wang J, Wang H: Downregulated tipe2 is associated with poor prognosis and promotes cell proliferation in non-small cell lung cancer. Biochem Biophys Res Commun 2015;457:43-49.

43 Cao X, Zhang L, Shi Y, Sun Y, Dai S, Guo C, Zhu F, Wang Q, Wang J, Wang X, Chen YH, Zhang L: Human tumor necrosis factor (tnf)-alpha-induced protein 8-like 2 suppresses hepatocellular carcinoma metastasis through inhibiting rac1. Mol Cancer 2013;12:149.

44 Gus-Brautbar Y, Johnson D, Zhang L, Sun H, Wang P, Zhang S, Zhang L, Chen YH: The anti-inflammatory tipe2 is an inhibitor of the oncogenic ras. Mol Cell 2012;45:610-618.

45 Zhang Z, Qi H, Hou S, Jin X: Tipe2 mrna overexpression correlates with tnm staging in renal cell carcinoma tissues. Oncol Lett 2013;6:571-575.

46 Ponten J, Saksela E: Two established in vitro cell lines from human mesenchymal tumours. Int J Cancer 1967;2:434-447.

47 Fogh J, Wright WC, Loveless JD: Absence of hela cell contamination in 169 cell lines derived from human tumors. J Natl Cancer Inst 1977;58:209-214.

48 Zhang YH, Yan HQ, Wang F, Wang YY, Jiang YN, Wang YN, Gao FG: Tipe2 inhibits tnf-alpha-induced hepatocellular carcinoma cell metastasis via erk1/2 downregulation and nf-kappab activation. Int J Oncol 2015;46:254-264. 